\title{
Flipped Classroom al laboratori
}

\author{
Jaume Molés Bort (moles.jaume@gmail.com) Màster Universitari en Professor/a d'Educació Secundària \\ Obligatòria i Batxillerat, Formació Professional i Ensenyaments d'Idiomes \\ Llorenç Monferrer Pons (monfer@uji.es) IES Professor Broch i Llop (Vila-real) Universitat Jaume I de Cas- \\ telló
}

En aquest article es proposa una experiència didàctica, implementada en l'assignatura "Mètodes Científics" del primer curs del Batxillerat Científicotècnic a l'IES Francesc Tàrrega de Vila-real. Amb l'objectiu principal d'aconseguir una millora educativa s'ha fet ús de la metodologia del "Flipped Classroom". La idea general és facilitar el contingut educatiu a l'alumnat perquè puga ser vist a casa o en el seu temps lliure, $i$ aprofitar les sessions al laboratori per a realitzar la part experimental col-laborativament de manera que els alumnes seran els qui porten la iniciativa de l'activitat.

Paraules clau: Flipped Classroom, vídeo, laboratori, experiments.

This paper proposes a learning experience, implemented in the course "Scientific Methods" for the first year of the Technical-scientific in upper secondary school studies at Francesc Tàrrega High School in Vila-real. With the aim of achieving an educational improvement, a "Fliped Classroom" methodology has been used. The general idea is to provide educational content to students who will work with it at home and, thus, take advantage of the laboratory sessions in which students will perform the experimental and collaborative work. In this manner, the students will take the initiative during the activity.

Key words: Flipped Classroom, video, laboratoy, experiments.

\section{INTRODUCCIÓ}

El "Flipped classroom" o "Classes a l'inrevés" (Castro, 2011) és un nou mètode d'ensenyament que inverteix els models tradicionals d'ensenyament, donant instruccions online des de fora de la classe i traslladant els deures dins de la classe. És a dir, consisteix a facilitar el contingut educatiu en vídeo, el qual pot ser vist pels estudiants en casa o en el seu temps lliure, al seu propi ritme i aprofitar el moment de la classe per realitzar la part pràctica (exercicis, experiments), discutir, analitzar, etc. D'aquesta manera s'aconsegueix que la sessió de classe siga més amena i interactiva. És a dir, durant les classes, se'ls ha de deixar opinar i al mateix temps indagar (Finkel, 2008).

La incorporació dels vídeos a l'educació permet introduir a l'aula o als espais personals de treball de l'estudiant realitats de difícil accés per la seva llunyania, pel requeriment de grans equips, o simplement per una qüestió d'eficiència en l'ús del temps. Alhora amb el vídeo es disminueix l'abstracció que comporten certs continguts si solament es presenten mitjançant el missatge oral o escrit (Ferrés, 1997).

El mètode tradicional representa el professor com la persona que imparteix la classe i mana deures per al dia següent. En el nou model el professor exerceix com a guia mentre els alumnes treballen a classe. Així mateix, la tecnologia i les activitats d'aprenentatge són dos components clau d'aquest nou model. Tots dos influencien l'entorn d'aprenentatge de l'estudiant de manera fonamental.

Menció especial en aquest model requereixen les rúbriques d'avaluació. Aquestes són una pode- 
rosa ferramenta per al docent que li permeten avaluar d'una manera més objectiva, ja que els criteris estan explícits i són coneguts de primera mà per tothom i no es poden canviar arbitràriament (Martínez-Rojas, 2008). Per tant, es podria dir que es tracta d'una ferramenta eficaç per implicar l'alumnat en el procés d'ensenyança-aprenentatge. Juntament amb el plantejament d'activitats complementàries i l'observació del treball realitzat pels alumnes, proporcionaran al professorat tota la informació necessària per a verificar que els alumnes hagen adquirit els objectius plantejats. També ens permetran indagar sobre la seva pràctica docent per tal de reorientar-la si cal.

Alguns dels avantatges que el Flipped Classroom [1] ofereixen són:

- Permet incrementar la interacció i la personalització de l'aprenentatge entre el professor i els estudiants.

- Constitueix un ambient on els estudiants agafen responsabilitat del seu propi aprenentatge.

- El professor deixa de ser el centre d'informació i es converteix en facilitador d'eixa informació.

- Facilita que els estudiants puguen aprendre al seu propi ritme $\mathrm{i}$ es fiquen al dia en cas d'absència.

- Com que es treballa en una plataforma digital, els alumnes poden interactuar amb companys i professors per a compartir els dubtes.

- Permet treballar col-laborativament, i per tant, ajuda a integrar-se en un col-lectiu, compartir ocupacions, coordinar esforços, trobar vies per solucionar problemes i exercir responsabilitats (Sanmartí, 1995).

\section{OBJECTIUS}

Per tal d'aconseguir una millora educativa, els principals objectius que volem assolir són:

- Fomentar l'autonomia de l'alumne, fent-lo més responsable del seu propi aprenentatge i que aquest siga un aprenentatge cooperatiu (on l'alumne s'implique directament) dintre d'un ambient collaboratiu (on tots els membres de la classe formen part del grup de treball).

- Que comprenguen determinats processos, tant físics com químics, a partir del disseny d'experiències senzilles que els puguen resultar cridaneres. És per això que treballarem per una costat els canvis d'estat a partir de la sublimació del iode $i$, per l'altre dues reaccions químiques en les quals intervenen el sodi i l'aigua oxigenada, respectivament.

\section{ACTIVITAT}

La proposta presentada està pensada per a implementar-se en sis sessions (Taula 1). Abans de la primera sessió, es crea un model de lloc web [2] fent ús de la plataforma Google Sites. En ell s'ofereixen als alumnes vídeos de bona qualitat d'àudio i imatge, suficientment atractius per a poder "enganxar-los" en el tema de treball i, sobretot amb una quantitat d'informació mesurada. No es vol saturar l'alumne amb un excés d'informació per la qual cosa haurà de prevaldre la qualitat front a la quantitat. Els vídeos que s'han seleccionat corresponen al programa Kopèrnik, programa dedicat a la divulgació científica [3].

\begin{tabular}{|c|c|c|c|c|}
\hline SESSIÓ & DATA & ESPAI & AGRUPACIÓ & TASQUES/METODOLOGIA \\
\hline \multirow{4}{*}{1} & \multirow{4}{*}{$22 / 04 / 2013$} & \multirow{4}{*}{$\begin{array}{l}\text { Laboratori/ } \\
\qquad \text { Aula } \\
\text { Informàtica }\end{array}$} & \multirow{4}{*}{ Grup Classe/Individual } & $\begin{array}{l}\text { Explicació de l'activitat i les } \\
\text { rúbriques d'avaluació }\end{array}$ \\
\hline & & & & Presentació del lloc web \\
\hline & & & & Contracte d'aprenentatge \\
\hline & & & & Autoritzacions Pares \\
\hline 2 & $23 / 04 / 2013$ & $\begin{array}{l}\text { Laboratori/ } \\
\text { Pati } \\
\text { Exterior }\end{array}$ & Grup Classe & $\begin{array}{c}\text { Pràctica 1 } \\
\text { Reacció del Sodi amb Aigua }\end{array}$ \\
\hline 3 & $24 / 04 / 2013$ & Laboratori & Grup Classe & $\begin{array}{c}\text { Pràctica 2 } \\
\text { Reacció del Peròxid d'Hidrogen }\end{array}$ \\
\hline 4 & $26 / 04 / 2013$ & Laboratori & Grup Classe & $\frac{\text { Pràctica } 3}{\text { Generació dels vapors de Iode. }}$ \\
\hline 5 & $29 / 04 / 2013$ & Laboratori & Grup Classe & $\begin{array}{l}\text { Millora de la secció web: } \\
\text { "Normes de Seguretat" }\end{array}$ \\
\hline 6 & $30 / 04 / 2013$ & $\begin{array}{l}\text { Laboratori/ } \\
\text { Aula } \\
\text { Informàtica }\end{array}$ & Grup Classe/Individual & $\begin{array}{c}\text { Finalització i edició digital de la } \\
\text { millora de "Les Normes de } \\
\text { Seguretat al Laboratori" }\end{array}$ \\
\hline
\end{tabular}

L'alumnat tindrà un dia límit per a penjar les activitats a realitzar.

Taula 1. Temporització de les sessions

S'han seleccionat experiències on el seu desenvolupament siga compatible amb els materials que es disposa al laboratori i la interpretació de les quals siga possible en el marc dels models elementals de reacció. Aquestes experiències seran les que visualitzaran abans de cada sessió i després reproduiran de forma col-laborativa al laboratori, enregistrant i editant tot aquest material audiovisual per a, finalment, penjar-lo al lloc web.

Respecte a l'avaluació s'ha pensat en un procés d'avaluació que intente cobrir els diferents moments avaluatius (avaluació inicial, formativa i final) dins el procés d'ensenyament-aprenentatge.

Per a l'avaluació inicial està previst l'ús d'un test de coneixements previs, com a un instrument d'avaluació, que es realitzarà a l'inici de cada sessió. 
A l'última sessió programada se'ls torna a passar el mateix test per a determinar l'evolució que han tingut i els èxits que han aconseguit.

Com treballem l'avaluació formativa? Doncs durant la realització de la pràctica els propis alumnes, amb les corresponents indicacions del professor, se n'adonen de quines qüestions han contestat bé o malament perquè estan realitzant la pràctica per ells mateix. Fem servir les rúbriques del treball experimental i l'actitud [4].

Els criteris d'avaluació per a l'avaluació final sumativa apareixen la figura 1. Tota l'explicació detallada d'aquestos criteris d'avaluació es troba a la secció d'Avaluació del lloc web.

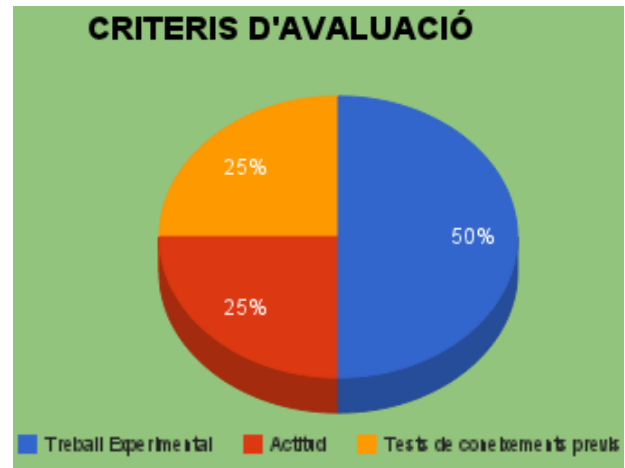

Figura 1. Criteris d'avaluació de l'activitat

\section{Sessió primera}

Se'ls comenta en què consisteix la metodologia "Flipped Classroom" i se'ls presenta el lloc web (figura 2). Es reparteixen les tasques a realitzar al web: Tasca d'edició de vídeos i fotos, Tasca de Manteniment i Millora del lloc web i Tasca de Correctors Lingüístics.

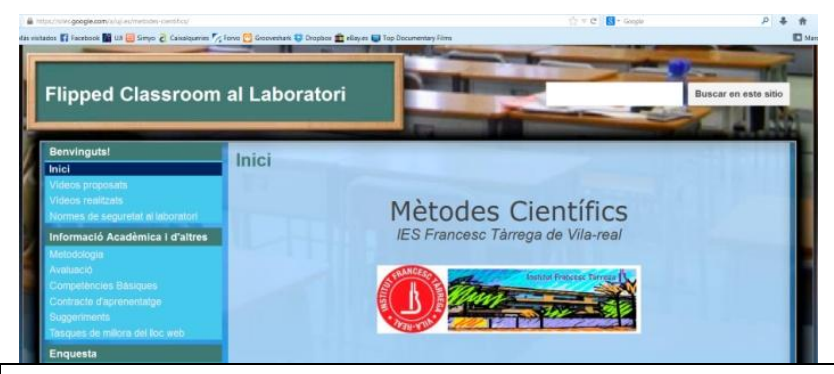

Figura 2. Lloc web de l'experiència didàctica

S'explica punt a punt els diferents apartats que formen el lloc web. Dintre de la secció de "Vídeos proposats" [5] es troba el vídeo que han de visualitzar a casa seua per a la propera sessió. Hauran de ficar comentaris al respecte per deixar per escrit les seues sensacions respecte de l'activitat, els dubtes i les inquietuds que els puguen sorgir així com prendre nota de tot el que necessiten per a reproduir al dia següent aquesta pràctica al laboratori.

També es presenta la secció "Vídeos realitzats" on es dipositaran els vídeos i tot el material fotogràfic editat pels alumnes.

Se'ls mostra una secció de "Normes de Seguretat al laboratori" on es troben les diferents Normes de Seguretat que hi ha d'haver en un Laboratori, així com l'etiquetatge dels Productes Químics i els Primers Auxilis. Aquesta secció, seguint un model tradicional d'exposició de material didàctic, té un aspecte poc atractiu ja que està molt carregada de text i té un aspecte poc visual. A les dues últimes sessions, se'ls proposarà fer una modificació d'aquest apartat per aconseguir que siga més atraient i visual.

A la secció "Contracte d'Aprenentatge" es troba el Contracte d'Aprenentatge que han d'omplir individualment i després penjar-lo en forma de comentari. Així cada alumne es compromet a complir el citat contracte. En aquesta secció també es troba el contracte del professor, correctament complimentat i penjat en forma de comentari a la pàgina web. També, a l'última sessió, hauran de complimentar una enquesta que ens donarà una idea de les sensacions de l'alumnat front aquesta activitat. Finalment es comenta com seran avaluats.

\section{Sessions segona, tercera i quarta}

Durant els primers 5' de cada sessió, hauran de complimentar el test de coneixements previs (figura 3) mitjançant el qual es vol saber si els alumnes han visualitzat el vídeo que se'ls demanava i al mateix temps, recollir informació suficient per a poder fer una avaluació diagnòstica inicial de cada alumne (Sanmartí, 1995).

Una vegada finalitzat el test, els alumnes es repartiran les diferents tasques (recerca i preparació del material, realització de la pràctica, enregistrament en vídeo, neteja del material, etc.) per a realitzar i experimentar la pràctica proposada amb els recursos propis del laboratori mentre s'enregistren i es fotografien. També es resoldran els dubtes que han sorgit a casa $\mathrm{i}$ es proposaran variants a l'experiment que han vist. Finalment, editaran a casa tot aquest material i el penjaran al lloc web (figura 4). 
Els vídeos triats no han de considerar-se com a propostes "tancades". Així, el professor fomentarà i promourà un entorn d'aprenentatge perquè l'alumne puga fer-se preguntes i aquestes puguen donar lloc a posteriors investigacions.

TEST PREVI VÍDEO SESSIÓ DIMARTS 23 D'ABRIL 2013 NOMI COGNOMS NOTA:

\begin{tabular}{|l|l}
\hline 1. & El sodi $\mathrm{i}$ el potassi són considerats com a: \\
\hline & Alcalins. \\
\hline & No metalls. \\
\hline & Terris. \\
\hline $\mathbf{2}$ & Cap de les anteriors. \\
\hline & Què són les bombolles que apareixen a la fenolftaleina? \\
\hline & $\mathrm{Naz} O$ \\
\hline & $\mathrm{Na}(\mathrm{OH})$ \\
\hline & Hidrogen i oxigen \\
\hline $\mathbf{3}$ & Hidrogen \\
\hline & El Na no reacciona amb aigua. \\
\hline & Veritat. \\
\hline $\mathbf{4}$ & Fals. \\
\hline & La fórmula del clorur de sodi és: \\
\hline & NaCl \\
\hline & Naz Cl \\
\hline & NaCl \\
\hline 5. & Capde les anteriors. \\
\hline & A casa nostra podem trobar el sodi a la sal comú \\
\hline & Veritat. \\
\hline & Fals. \\
\hline
\end{tabular}

Figura 3. Test de coneixements previs

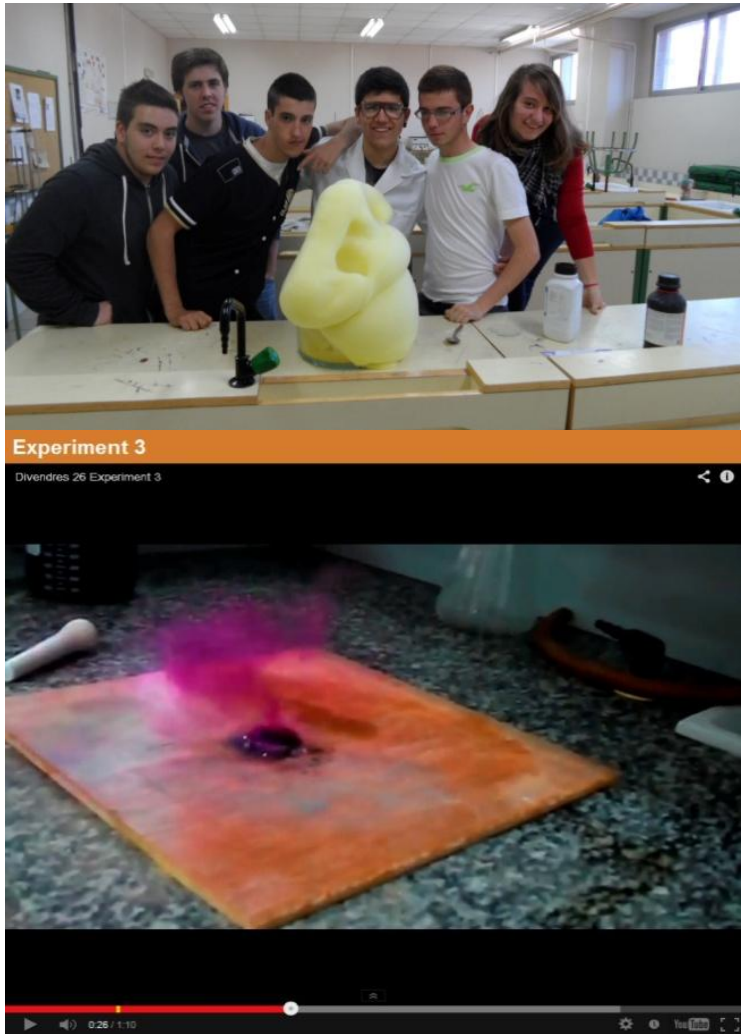

Figura 4. Exemples del material audiovisual

\section{Sessions cinquena i sisena}

Aquestes són sessions pensades per a fer suggeriments per part de l'alumnat per tal de millorar la pàgina web. Per aconseguir-ho, s'utilitza una Tècnica d'Aprenentatge Col-laboratiu (TAC) per al diàleg anomenada "La roda d'idees" (Barkley, 2005). Els alumnes generen una pluja d'idees que permet la participació de tots els estudiants. La proposta escollida consistirà a realitzar una millora de la secció de Normes de Seguretat; fer-la més visual i atractiva. Així doncs, cadascú es llegirà les Normes de Seguretat, pensarà formes de modificar el text $i$ farà recerca d'imatges (les que no es puguen realitzar al laboratori) per Internet.

Les escenes que es puguen representar al laboratori es faran fent ús d'una TAC per a l'ensenyament recíproc: "El joc de rol" (Barkley, 2005). Cadascú haurà d'assumir una identitat diferent (alumnes complidors de les normes, alumnes despistats i alumnes que no volen complir-les) i representar l'escena que se li demana, per tal de poder "immortalitzar-la" en una fotografia [6].

Finalment, es fixa un dia límit i els alumnes lliuren complimentada l'enquesta, així com tot el material editat i penjat, i se'ls lliuren les notes en funció dels criteris d'avaluació que es troben a la secció "Avaluació" del lloc web.

\section{MATERIAL I RECURSOS}

En aquesta experiència s'han emprat els recursos que es mostren a la Taula 2.

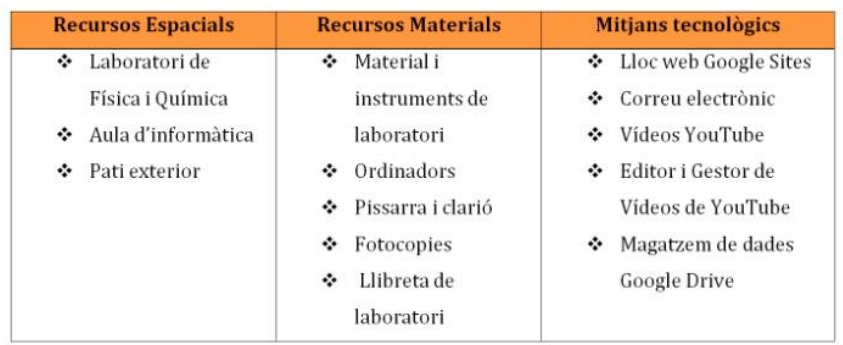

Taula 2. Material i recursos de l'activitat

\section{AVALUACIÓ DE L'ACTIVITAT}

Per tal de veure si l'activitat ha resultat positiva tornarem als objectius que ens vam plantejar:

Respecte al primer objectiu: "Fomentar l'autonomia de l'alumne, fent-lo més responsable del seu propi aprenentatge $i$ que aquest siga un 
aprenentatge cooperatiu dintre d'un ambient colllaboratiu"

- Els alumnes han participat més a les classes, l'activitat ha sigut molt atraient per a l'alumnat $i$, en cas de ser possible, el $100 \%$ de l'alumnat voldria repetir-la, segons les dades de l'enquesta realitzada (fig. 5).

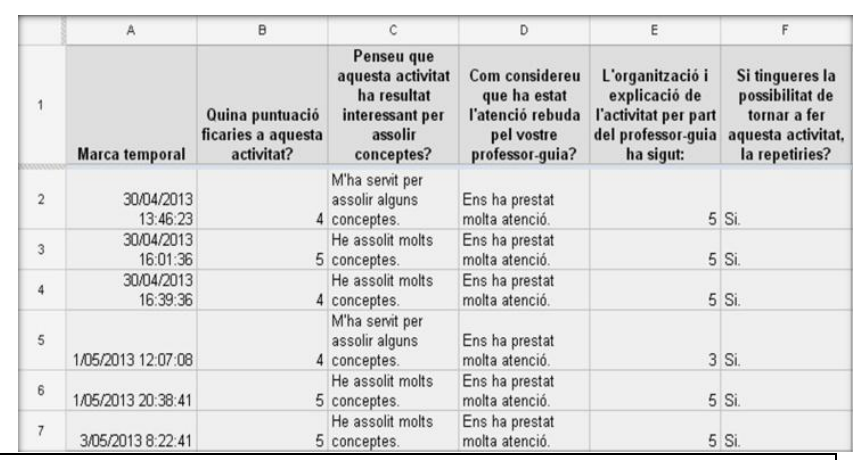

Figura 5. Resultats Enquesta dels alumnes

Respecte al segon: "Que comprenguen determinats processos, tant físics com químics, a partir del disseny d'experiències senzilles que els puguen resultar cridaneres".

- Segons l'opinió d'en Maties Marín, el seu professor de l'assignatura i Tutor del Pràcticum: "Les qualificacions de l'assignatura han augmentat degut a una elevada participació dels alumnes. L'activitat els ha resultat interessant perquè les reaccions "espectaculars" són molt atraients per a ells, el que fa que s'interessen pels processos químics i les seues aplicacions. A més de la participació directa en l'activitat de laboratori, el fet que hagueren de participar mitjançant Internet amb comentaris, contracte, etc... ha motivat que s'involucren més en el procés d'aprenentatge".

\section{CONCLUSIONS}

Com a docents hem pogut observar que la Flipped Clasroom és un model que ha ajudat als estudiants a assolir els objectius marcats. El plantejament de l'activitat també ens ha resultat positiva perquè els alumnes han conegut una sèrie d'eines útils en el seu aprenentatge com han estat les rúbriques d'avaluació, el contracte d'aprenentatge, les enquestes d'avaluació i millora, les TAC, etc. L'ús del lloc web els ha ajudat a tindre a la seua disposició tot el material ben ordenat i classificat. A més, han fet ús, entre d'altres, d'aplicacions i pro- grames de gestió i edició de vídeos com és el gestor i editor de vídeos de Youtube.

Per altra banda, aquesta metodologia ha potenciat el treball per indagació. Els alumnes han mostrat desitjos d'aprendre més. Així, entre d'altres s'han fet preguntes sobre les observacions, han proposat modificacions dels experiments que han permès veure millor la reacció exotèrmica entre el sodi i l'aigua o bé han introduït altres metalls com l'alumini (degut a la impossibilitat de tenir magnesi en pols al laboratori) en la sublimació del iode. Han cooperat amb els companys, han comunicat a través d'Internet els seus productes finals, en definitiva han acceptat la "invitació a aprendre".

\section{"El potassi o magnesi també reaccionen així? \\ "Aquest vapor sols pot fer-lo el iode?}

"Este vídeo me parece muy interesante porque muestra una reacción exotérmica muy vistosa, nosotros en clase hemos hecho esta practica poniendo el sodio en un pequeño barco de papel para mostrar mejor la reacción exotérmica que se produce con la mezcla del sodio y el agua. Creo que es una de las reacciones que me ha gustado mas preparar"

Malgrat tots els avantatges que s'han pogut observar, pensem que els alumnes haurien de participar més activament en el web. Tenim clar que els alumnes entren, visualitzen els vídeos i alguns fiquen comentaris, però la gran majoria no saben què escriure $\mathrm{i}$ així ens ho comuniquen. Com a proposta de millora si després de cada sessió se'ls planteja una espècie de diari reflexiu amb preguntes específiques com: Què he aprés a la sessió de hui?, Què no he entès?, etc., amb la seua corresponent rúbrica d'avaluació (Martínez-Rojas, 2008) tal vegada aconseguiríem solucionar el problema.

\section{REFERÈNCIES}

BARKLEY, E., CROSS, P., HOWELL, C. (2005). Tècniques d'aprenentatge collaboratiu. Ed. Morata/MEC, 2007.

CASTRO MEDINA, J. (2011). Què és la Flipped Classroom?. Revista Digital Queaprendemoshoy.com.

$<$ http://queaprendemoshoy.com/flipped-

classroom/\#.T6fOBFJTHTq> 
FERRÉS, J. (1997). Vídeo i educació. Barcelona: Paidós.

FINKEL, D. (2008). Donar classe amb la boca tancada. Revista electrònica al voltant de l'ensenyança de l'Economia Pública, 6, 49-60.

MARTÍNEZ-ROJAS, J.G. (2008). Les rúbriques a l'avaluació escolar: la seua construcció i el seu ús. Revista Colombiana d'Avanços en Medició, 6, 129-134.

SANMARTÍ, N. (1995). L'avaluació diagnòstica inicial. En N. Sanmartí, Projecte docent i investigador de didàctica de les ciències (pp. 95-139). Barcelona: Universitat Autònoma de Barcelona.

[1] Disponible a:

http://www.theflippedclassroom.es/

[2] Disponible a:

https://sites.google.com/a/uji.es/metodes-cientifics/

[3] Disponible a:

https://www.youtube.com/watch?v=xdojRnGu02U
[4] Disponible a:

https://sites.google.com/a/uji.es/metodescientifics/avaluacio

[5] Disponible a:

https://sites.google.com/a/uji.es/metodescienti-

fics/assignments/videoperavisualitzarabansdela sessiodeldivendres26dabril

[6] Disponible a:

https://sites.google.com/a/uji.es/metodescientifics/my-forms

\section{AGRAIIMENTS}

En tot treball es necessita disposar de l'ajuda per part dels altres i d'un temps necessari que, en segons quins moments, fa falta. M'agradaria destacar el meu tutor de Pràcticum, en Maties Marín Sáez, pel tracte rebut, la seua ajuda i sobretot la llibertat permesa a l'hora d'utilitzar la docència de la seua assignatura de Mètodes Científics. Finalment, agrair el tracte rebut per part dels alumnes i del personal del centre. 